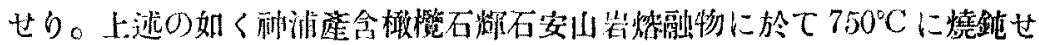
ろものも球顆状微晶を生ずるは，試料大なる在以下燒釛温度 $750^{\circ} \mathrm{C}$ と微晶

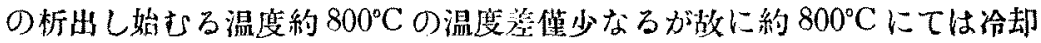
速度極めて䌊慢なるによるべし。

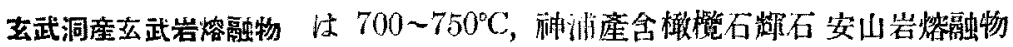
は $650 \sim 700^{\circ} \mathrm{C}$ の間の温度に於て霄氣的性質を急變するは微晶或は晶子の 晶出に因ること明らかなり。然して兩滵融物の温度の相違は結晶作用の難 易に因る心゙し。工業的立場より照基性岩石熔融物に良電氣的性貿在賦與せ

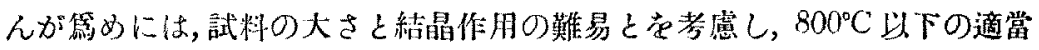

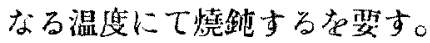

\title{
仙臺市外三瀧附近に弡澾せる安山岩梊 玄武岩中の斜長石に就て
}

理學士 根本忠寬

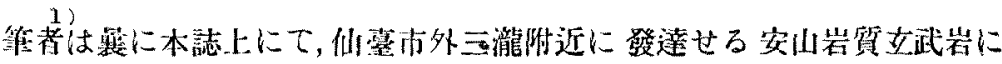
就きて報告せり。その祭岩床 (2)中に含まる>科長石を斑昆及び緗晶の 2

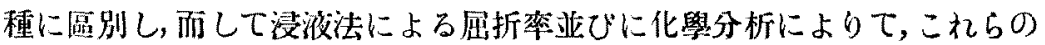
斜長石の成分在次の如く決定せり。(第一表)。

\begin{tabular}{|c|c|c|}
\hline 第 & 表 \\
\hline Imnenersion method & An 95 & An 65 \\
\hline Chemical aualysis & An 95.1 & $\ldots \ldots$. \\
\hline
\end{tabular}

筆者は前報交に於て，玟 狀灰長石はその大さ異常に 大なるに拘らず, 累嬊構造 は一般に不完全にして, 唯 その周總部に於てのみ $1 / 20$

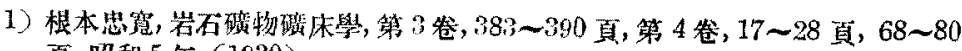
頁, 昭和 5 年 (1930). 
～1/30 mm の厚さに亚り稍明滕なる事在指摘し，且この周秝部は，化學成分 に於て斑晶の主要部分とは诸しく翼な゙り，管る石基科長石のそれに近似せ るものか，或は全く同一のものなる心ししと報じたるも，常時唒その成分を明 かにするを得ざりき。

その後 universal stage の使用により，上記の斜長石及びその他の科長石 の化學成分を明かにするを得たるを以て, 前報文の補遗として玆にその結 果在記述せんとす。

Universal stage は Leitz 斻裂 SY 型袁老朋る，その使朋法は鈴木教授の指 導に基つきき，M. Berek ${ }^{23}$ 氏の方法に上れり。科長石の成分決定には，M. Berek 氏の direkte Verfahren 及びZwillingselemente の 2 方法を用るたり。

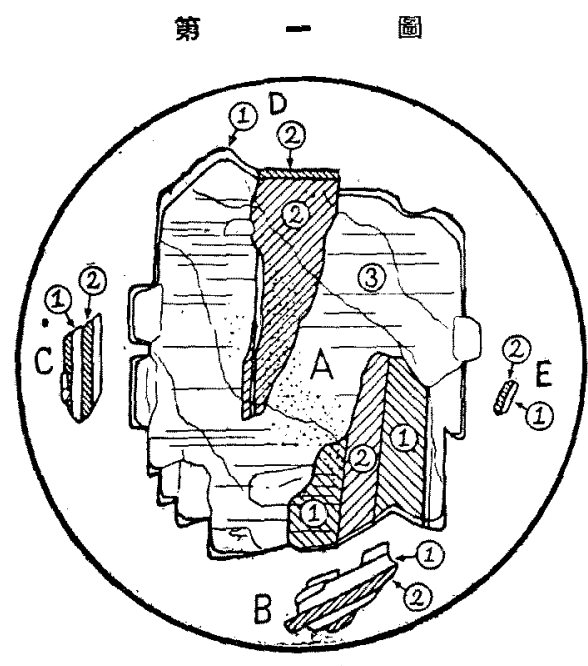

15
A......A. 2
D.....D. 1
B...... B. 5
E...... E. 4
C....... C. 2

1) 前出, 第 4 㾞, 70 頁, 昭和 5 年 $(1990)$.

2) M. Berek, Mikroskopische Mineralbestimunung mit Hille der Universaldrehtischm theden. (Berlin), 1924.
即ち前者は淔授に测定し たる光軸角の值より斜長 石の成分在決定する方法 にして, 後者は双晶朝よ

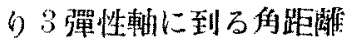
$\left(\mathrm{n}_{\alpha}, \mathrm{n}_{\beta}, \mathrm{n}_{\gamma}\right)$ 居求め, これ らの3值老坐標朝として 投影し，その成分在决定 す方方法なり。 この测定は, 本地域に 發達す万 4 岩床中, 最 も 代表的なる碞床 (2)に就 いて行ひたるものにして 


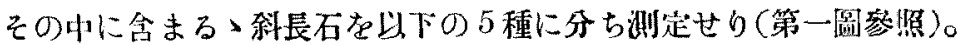

A. 琣狀斜長石中最も多量に存在し，從つて最も主要なるものにして，そ

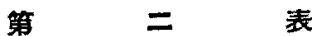

\begin{tabular}{|c|c|c|c|c|c|c|c|c|c|c|}
\hline \multirow{2}{*}{$\begin{array}{l}\text { No. of } \\
\text { Crystal }\end{array}$} & \multicolumn{4}{|c|}{ Direct method } & \multicolumn{6}{|c|}{ Twaning-element } \\
\hline & Indivi. & Char. & $2 \mathrm{~V}$ & An\% & Incivi. & Twin & $\mathrm{n}_{\alpha}$ & $\mathrm{n}_{\beta}$ & ni & An $\%$ \\
\hline A. 1 & $\begin{array}{l}1 \\
2 \\
3\end{array}$ & - & $76^{\circ}$ & $A_{n_{100}}$ & $\left.\begin{array}{l}1 \\
2 \\
1 \\
2\end{array}\right\}$ & $\begin{array}{c}\text { Pericline } \\
\text { Albrite- } \\
\text { Carlsbad }\end{array}$ & $\begin{array}{l}50 \\
79\end{array}$ & $\begin{array}{l}64 \\
27\end{array}$ & $65 \frac{1}{2}$ & $\begin{array}{l}A n_{99} \\
A n_{98}\end{array}$ \\
\hline A. 2 & $\begin{array}{l}2 \\
3\end{array}$ & - & $\begin{array}{l}78^{\circ} \\
76^{\circ} \\
77^{\circ}\end{array}$ & $\begin{array}{l}A n_{85} \\
A_{100} \\
A_{n_{95}}\end{array}$ & $\left.\begin{array}{l}1) \\
2\} \\
2 \\
3 \\
1 \\
3\end{array}\right\}$ & $\begin{array}{l}\text { Albite } \\
\text { Carlsbad } \\
\begin{array}{c}\text { Albite- } \\
\text { Carlsbad }\end{array}\end{array}$ & $\begin{array}{l}55 \\
37 \cdot \frac{1}{2} \\
78\end{array}$ & $\begin{array}{l}59 \frac{1}{2} \\
82 \\
30\end{array}$ & $\begin{array}{l}50 \frac{1}{2} \\
54 \\
62\end{array}$ & $\begin{array}{l}A n_{91} \\
A r_{97} \\
A n_{94}\end{array}$ \\
\hline A. 3 & $\begin{array}{l}1 \\
2\end{array}$ & - & $\begin{array}{l}78^{\circ} \\
75^{\circ}\end{array}$ & $\begin{array}{l}A_{n_{88}} \\
A_{100}\end{array}$ & & Pericline & 53 & $61 \frac{1}{2}$ & 51 & $\mathrm{An}_{94}$ \\
\hline A. 4 & $\begin{array}{l}1 \\
2 \\
3\end{array}$ & - & $\begin{array}{l}76^{\circ} \\
75^{\circ} \\
78^{\circ}\end{array}$ & $\begin{array}{l}A n_{100} \\
A_{103} \\
A n_{88}\end{array}$ & $\left.\begin{array}{l}1 \\
2 \\
1 \\
3\end{array}\right\}$ & $\begin{array}{c}\text { Carlsbad } \\
\text { Albite- } \\
\text { Carlsbad }\end{array}$ & $\begin{array}{l}38 \frac{1}{2} \\
78\end{array}$ & $\begin{array}{l}85 \frac{1}{2} \\
28\end{array}$ & $\begin{array}{r}52 \frac{1}{2} \\
61 \frac{1}{2}\end{array}$ & $\begin{array}{l}A n_{94} \\
A n_{95}\end{array}$ \\
\hline A. 5 & $\begin{array}{l}1 \\
2\end{array}$ & - & $\begin{array}{l}76^{\circ} \\
78^{\circ}\end{array}$ & $\left\{\begin{array}{l}A n_{100} \\
A n_{88}\end{array}\right.$ & & Carlsbad & 39 & 84 & 52 & $A n_{96}$ \\
\hline A. 6 & $\begin{array}{l}1 \\
2\end{array}$ & - & $\begin{array}{l}76^{\circ} \\
76^{\circ}\end{array}$ & $\begin{array}{l}A n_{100} \\
A n_{103}\end{array}$ & & Albite & $56 \frac{1}{2}$ & 62 & $46 \frac{1}{2}$ & $A n_{90}$ \\
\hline \multirow{2}{*}{ Mean } & & & & Ang5.9 & & & & & & $\begin{array}{r}\mathrm{An} \\
\quad 94.8 \\
\end{array}$ \\
\hline & \multicolumn{10}{|c|}{$\mathrm{An}_{95,4}$} \\
\hline
\end{tabular}

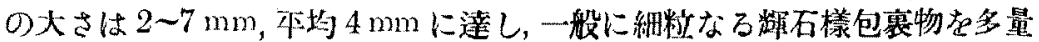
に含さ。6 結奛に就いて测定せる結果は第二表に示すが如し。この表によ つて明かなる如く，本测定の結果は 浸滀法及び化學分析によりて決定した る値と大體に於て一致せり。

B. A と共に斑贸結晶をなせども，第一圖に示すが如く，その大さは遥に 小にして 1 0.4, $\mathrm{mm}$ 平均 $0.8 \mathrm{~mm}$ 队外に過ぎず, 且数石㧼包裹物も極めて 少く, 又周緣部に於もる照帶情造もAの如くには明かならずして，A と明 
かに區別せらる。9 結晶に就きて测定せる結果は第三表に毁八らる。この 結果を第二表と比較するに, 斜長石の平均成分には大差なく, 唯僅かに前者

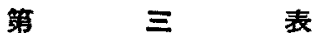

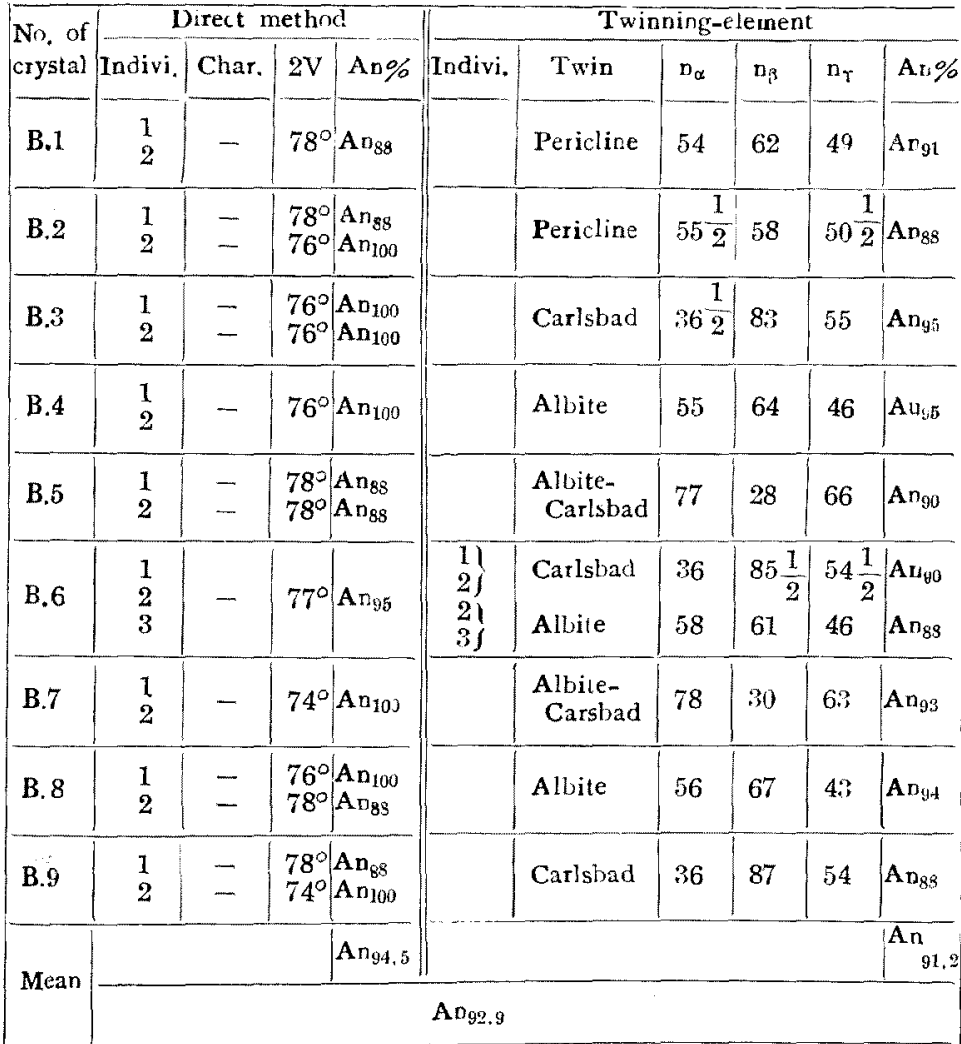

よりAn分子を減ずる傾问を示せり。

C. 結晶の大さ，輸姑，及び包裹物の有無等によつては全くBと區別する 能はずして, universal stage の使用により初めてその存在明かとなれり。任 意に選擇せる小なる斑状科長石 11 の中，9はBに屬し，僅かに2のみCに 属するを以て、この種の斜長石はBに比し極めて少量に存在するものなる 
ベし。これらの2結晶に就いて测定せる結果は第四表に示すが如く，Bに 比し遥か心An 分子を城ず。

第

四表

\begin{tabular}{|c|c|c|c|c|c|c|c|c|c|}
\hline \multirow{2}{*}{$\begin{array}{l}\text { No. of } \\
\text { crystal }\end{array} \mid$} & \multicolumn{4}{|c|}{ Direct method } & \multicolumn{5}{|c|}{ Twinning-element } \\
\hline & Indivi. & Char. & $2 \mathrm{~V} \mid$ & An\% & Twin & $\mathbf{n}_{\mathscr{\alpha}}$ & $n_{\beta}$ & $\mathrm{n}_{\gamma}$ & $A n \%$ \\
\hline$C \cdot 1$ & $\begin{array}{l}1 \\
2\end{array}$ & $=$ & $\begin{array}{l}84^{\circ} \\
84^{\circ}\end{array}$ & $\begin{array}{l}\mathrm{An}_{74} \\
\mathrm{~A} n_{74}\end{array}$ & X-Pericline & 38 & 85 & $52 \frac{1}{2}$ & $\mathrm{An}_{76}$ \\
\hline C. 2 & $\begin{array}{l}1 \\
2\end{array}$ & - & $80^{\circ}$ & $A_{n} n_{81}$ & Albite & $62 \frac{1}{2}$ & $60 \frac{1}{2}$ & 43 & $\mathrm{An}_{79}$ \\
\hline \multirow{2}{*}{ Mean } & & & & $A n_{76.3}$ & & & & & $\mathrm{An}_{77,5}$ \\
\hline & \multicolumn{9}{|c|}{$\mathrm{An}_{76,9}$} \\
\hline
\end{tabular}

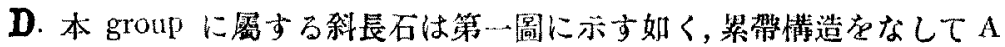

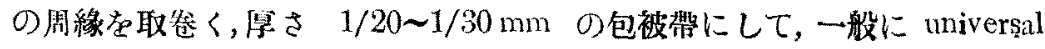
stageによる成分の决定困難なれ ぞも，その中厚さ約 1/13 1/15 mm の稍厚 き包被帶ななる な3結晶に就き测定せる結果は第五表に示さる。直接法によ りて與へらるい斜長石の成分と，双晶要素によりて決定さる、成分とが，本 均値に於て $6.2 \%$ の差を示すは，本科長石が上記の如き薄き包被带をなす 篇めに，测定上の誤差が前三者に比して 大なる篇めなるべし。本測定の結 果在Cのそれと比校するに，その本均値に於て大全なく，唯僅かにAn分子 を減ずる倾向有す。

この包被㴖は A 結晶の最外側をなすものに非ずして,更にこの包被帶の 外側には栖めて薄き包被燕存在すれども，その成分決定は不可能なり。累 带棈造の順序より考察せば,この最外側の包被帶は石基科長石と近似せる 成分在有するるのなるべし。

E. 前 4 者と異なり, 本 group に屬する科唇石哇石基中に存在する短朋狀 の細晶なり。前報文にて記せる如く，本岩の石基は比較的粗柆なれども，普 


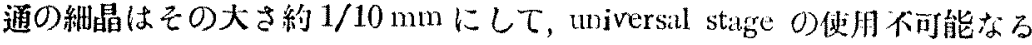
を以て，それらの中比较的大なるもの, 即ち齿通の紐晶の約 $2 \sim 3$ 偖大のb

第

五

表

\begin{tabular}{|c|c|c|c|c|c|c|c|c|c|}
\hline \multirow{2}{*}{$\begin{array}{l}\text { No. of } \\
\text { crystal }\end{array}$} & \multicolumn{4}{|c|}{ Direct method } & \multicolumn{5}{|c|}{ Twinning-element } \\
\hline & Indivi. & Char. & $2 \mathrm{~V}$ & An\% & Twin & $n_{\alpha}$ & $n_{\beta}$ & $\mathrm{n}_{\mathrm{r}}$ & An\% \\
\hline D.1 & $\begin{array}{l}1 \\
2\end{array}$ & - & $\begin{array}{l}84^{\circ} \\
86^{\circ}\end{array}$ & $\begin{array}{l}A n_{74} \\
A n_{71,5}\end{array}$ & Carlshad & $\therefore 4$ & $86 \frac{1}{2}$ & 56 & $A \mathrm{n}_{j}$ \\
\hline D. 2 & $\begin{array}{l}1 \\
2\end{array}$ & $\overline{-}$ & $\begin{array}{l}90^{\circ} \\
86^{\circ}\end{array}$ & $\begin{array}{l}A n_{68,5} \\
A n_{71,5}\end{array}$ & Periclite & 62 & 60 & $43 \frac{1}{2}$ & $\Delta_{n_{75}}$ \\
\hline D.3 & $\begin{array}{l}1 \\
2\end{array}$ & - & $\begin{array}{l}86^{\circ} \\
84^{\circ}\end{array}$ & $\begin{array}{l}\Delta n_{71.5} \\
A n_{74}\end{array}$ & Carlsuad & 34 & 87 & 56 & $\mathrm{An}_{80}$ \\
\hline \multirow{2}{*}{ Mean } & & & & $\mathrm{An}_{71,8}$ & & & & & $\mathrm{An}_{78,0}$ \\
\hline & \multicolumn{9}{|c|}{$\mathbf{A n}_{74,9}$} \\
\hline
\end{tabular}

第六表

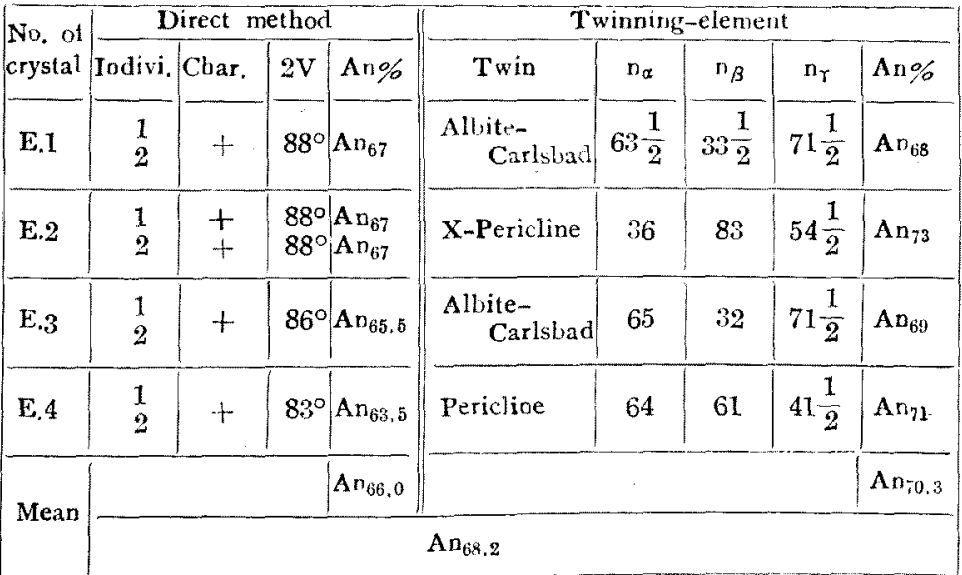

の5在簒び測定せり。その結果は第六表に示すが如し。本結果はその結晶 が小なる䉆め, Dの場合と同樣に测定上の誤差おらんも, 浸淁法によりて 决定したるる值（第一表參照）と近似せるを胃るべし。 
第二表乃至第六表に示す如く，個々の結晶に就いて测定せる結果は，必ず しもよく一致せず。それは各絬晶の多少の成分の差違，及び一双晶に於て その左右兩片の成分の不同による事あらんも，筆者は本测定法の性質上，充

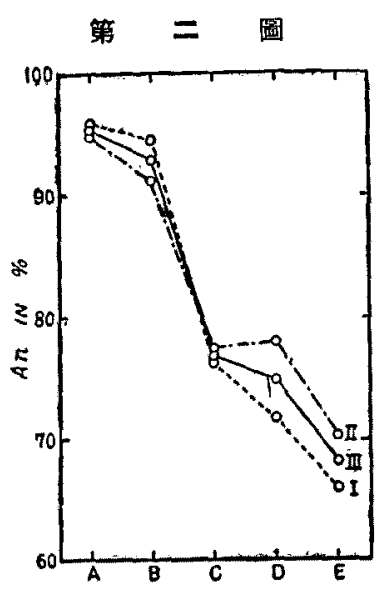

1. The mean value oltained by the direct method.

II. The mean value obtaired by the twinning-element.

III. The mean value of I and II.

分注意しつ、测定を行八ども，唒上諟の 惯際の成分上の差違に比し, 比较的大な る测定上の誤差圶生ずべきものと信じ, 各它roupに就き测定せる 2 9 個の平均値 を以て各 group の成分を表す事とせり。 これらの本均値を圖示せば第二圖の 如 し。本圖によつて明かなる如く，本岩中 に念まる>斜長石はその成分によりて大

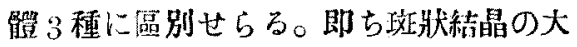
部分在与占め, $\mathrm{A1}_{95.4 \sim 92.9}$ O)成分在有方斜 長石と, $\mathrm{An}_{68.2}$ O)成分有する細晶以外に 極めて少量ながら $A n_{i 6,9}$ の成分存有する 小なる斑狀結晶, 及び $\Delta n_{7,9}$ の成分有 する灰長石周螕部の包被帶をなす斜長石 おり。

之によつて見るに，聇發成分に富める溶體中に於て 急激なる 結晶作咸觉 行ひ，從つて殘液と反哕作朋在行ふ遑なくして嗔出したるものと考へらる >本岩に於 $〕$ ，ての石基生成の時代に至る途中に於て， $\mathrm{An}_{76.9 \sim 74.9}$ の成分 有する科脣石を晶出せしむべき極めて短小なる晶出時期おりしものと考 几らる。

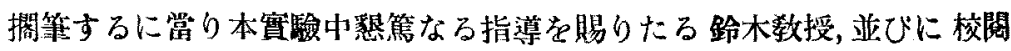
学睗りたる神津教授に深く謝嬑至す。 